\title{
PENGARUH AKTIVITAS OLAH RAGA DAN PERILAKU MEROKOK TERHADAP HIPERTENSI PADA LANSIA DI PUSKESMAS TOMINI KECAMATAN TOMINI KABUPATEN PARIGI MOUTONG TAHUN 2019
}

\author{
Arlianti $^{1^{*)}}$, Toha Muhaimin ${ }^{2)}$, Syamsul Anwar ${ }^{3)}$ \\ 1,2,3 Fakultas Ilmu Keperawatan Universitas Muhammadiyah Jakarta. 10510. \\ *Email:Nersanti26@gmail.com
}

\begin{abstract}
Abstrak
World Health Organization memperkirakan tahun 2025 akan ada penderita hipertensi 1,5 milyar orang setiap tahun. Di Indonesa prevalensi hipertensi penduduk umur 18 tahun ke atas sebesar 31,7\%. Tujuan penelitian adalah diketahuinya pengaruh aktivitas olah raga dan perilaku merokok terhadap hipertensi pada lansia di Puskesmas Tomini Kecamatan Tomini Kabupaten Parigi Moutong Sulawesi Tengah tahun 2019. Desain penelitian yang digunakan adalah analitik korelasional dengan pendekatan Cross sectional. Jumlah sampel dalam penelitian ini sebanya 114 orang di Puskesmas Tomini Kecamatan Tomini Kabupaten Parigi Moutong Sulawesi Tengah Tahun 2019. Penarikan sampel secara simple random sampling. Analisa data dengan menggunakan analisis univariat, bivariat dan multivariat dengan uji regresi logistik. Hasil analisis bivariat menunjukkan terdapat pengaruh aktivitas olah raga ( $p$-value $=0,000 \leq 0,05)$ dan perilaku merokok raga ( $p$-value $=0,001 \leq 0,05)$ terhadap hipertensi pada lansia di Puskesmas Tomini Kecamatan Tomini Kabupaten Parigi Moutong Sulawesi Tengah tahun 2019. Kesimpulan dalam penelitian ini yaitu terdapat pengaruh aktivitas olah raga dan perilaku merokok terhadap hipertensi pada lansia di Puskesmas Tomini Kecamatan Tomini Kabupaten Parigi Moutong Sulawesi Tengah tahun 2019. Disarankan kepada peneliti selanjutnya agar hal-hal yang sudah ada dalam penelitian ini bisa menjadi acuan dan dapat dikembangkan terutama pada variabel-variabel yang belum diteliti
\end{abstract}

Kata kunci: Olah Raga, Hipertensi, Lansia, Perilaku Merokok

\begin{abstract}
The World Health Organization estimates that in 2025 there will be hypertension sufferers 1.5 billion people every year. In Indonesia the prevalence of hypertension in the population aged 18 years and over is 31.7\%. The influence of sports activities and smoking behavior on hypertension was recognized by the elderly at Tomini Health Center, Tomini Subdistrict, Parigi Moutong District, Central Sulawesi in 2019. The research design used was correlational analytic with cross-sectional approach. The sample in this study was 114 elderly people at the Tomini Community Health Center, Tomini Subdistrict, Parigi Moutong District, Central Sulawesi in 2019, using simple random sampling. Data analysis using univariate, bivariate and multivariate analysis with logistic regression test. The results of bivariate analysis showed that there was an effect of sports activity ( $p$-value $=0,000) 0,05)$ and physical smoking behavior ( $p$-value $=0,001 \leq 0,05)$ on hypertension in the elderly at Tomini Puskesmas Tomini District, Parigi Moutong, Sulawesi Central 2019. The conclusion in this study is that there is an influence of sports activities and smoking behavior on hypertension in the elderly at Tomini Health Center Tomini Subdistrict Parigi Moutong District Central Sulawesi in 2019. It is recommended to the Tomni Health Center to routinely educate the public, especially hypertension sufferers about lifestyle influences which is not good at increasing blood pressure, as appropriate as smoking behavior and sports activities
\end{abstract}

Keywords: Sports Activities, Hypertension, Elderly, Smoking Behavior 


\section{PENDAHULUAN}

Peningkatan usia harapan hidup dan penurunan angka fertilitas mengakibatkan populasi penduduk lanjut usia meningkat. World Health Organization (WHO) memperkirakan akan terjadi peningkatan proporsi lansia di dunia dari $7 \%$ pada tahun 2020 sampai $23 \%$ pada tahun 2025 (Novitaningtyas, 2014). Bertambahnya jumlah lansia sebenarnya tidak menjadi masalah akan tetapi seiring dengan bertambahnya usia maka pada umumnya diiringi dengan semakin meningkatnya berbagai penyakit seperti hipertensi, diabetes mellitus maupun penyakit kronis lainnya. Hipertensi merupakan gejala peningkatan tekanan darah seseorang berada diatas normal yang mengakibatkan suplai oksigen dan nutrisi yang dibawa oleh darah terhambat sampai ke jaringan tubuh yang membutuhkan (Rawasiah 2014).

WHO memperkirakan tahun 2025 akan ada penderita hipertensi 1,5 milyar orang setiap tahun (Setyanda, 2015). Di Indonesa prevalensi hipertensi penduduk umur 18 tahun ke atas sebesar 31,7\% (Kemenkes, 2014). Penderita hipertensi di Propinsi Sulawesi Tengah yang didapat melalui pengukuran takanan darah pada umur $\geq 18$ tahun dengan prevalece rate sebesar 28,7\% (Trihono, 2013). Di Kabupaten Parigi Moutong Sulawesi Tengah berdasarkan data profil kesehatan Dinkes Kabupaten Parigi Moutong diketahui jumlah penderita hipertensi selama tahun 2015 sebanyak 72120 penderita atau prevalece rate $25,07 \%$. Khusus Puskesmas Tomini Kabupaten Parigi Moutong selama 2017 diketahui jumlah penderita hipertensi 848 pendrita atau prevalence rate $4,27 \%$ dengan lakilaki 406 penderita atau prevalence rate 3,99\% dan perempuan 442 penderita atau prevalence rate $4,57 \%$ (Sumber : Data P2M Puskesmas Tomini, 2017).

Sampai saat ini penyebab hipertensi esensial tidak diketahui dengan pasti.
Faktor resiko hipertensi adalah umur, jenis kelamin, riwayat keluarga, genetik, kebiasaan merokok, konsumsi garam, lemak jenuh, penggunaan jelantah, kebiasaan konsumsi minum-minuman beralkohol, obesitas, kurang aktifitas fisik, stres, penggunaan estrogen (Kemenkes RI, 2014). Peningkatan jumlah penderita hipertensi ini diakibatkan oleh perubahan gaya hidup yang salah satunya karena merokok. Merokok dapat menyebabkan hipertensi akibat zat-zat kimia yang terkandung di dalam tembakau yang dapat merusak lapisan dalam dinding arteri, sehingga arteri lebih rentan terjadi penumpukan plak (arterosklerosis).

Berdasarkan penelitian Lewa, dkk secara umum lansia yang tidak melakukan aktivitas fisik berhubungan dengan kejadian HST (Hipertensi Sistolik Terisolasi) yaitu dengan angka kejadian sebesar 2,336 kali beresiko terkena hipertensi (Novitaningtyas, 2014).

Berdasarkan Hasil studi wawancara Kepala Puskesmas Tomini diketahui lansia yang menderita hipertensi sebanyak 90 penderita dan 93 penderita Tahun 2018) disebabkan perilaku lansia 50\% adalah perokok dan kurangnya aktivitas olah raga.

Dampak dari tekanan darah yang selalu tinggi dan berlangsung lama maka sangat berpotensi terhadap pecahnya pembuluh darah otak yang dapat menyebabkan kerusakan sel saraf sehingga terjadi kelumpuhaan organ sampai berujung kematian. Peningkatan tekanan darah yang disebabkan oleh aktivitas yang kurang akan menyebabkan terjadinya komplikasi seperti penyakit jantung koroner, gangguan fungsi ginjal, stroke dan sebagainya (Novitaningtyas, 2014). Hipertensi juga merupakan faktor resiko utama untuk terjadinya penyakit kardiovaskular. Apabila tidak ditangani dengan baik, hipertensi dapat menyebabkan stroke, infark miokard, 
gagal jantung, demensia, gagal ginjal dan gangguan pengelihatan (Arifin, 2016).

\section{METODE}

Desain penelitian adalah analitik korelasional dengan pendekatan cross sectional. Berdasarkan tujuan penelitian, termasuk penelitian korelasi karena bertujuan mengetahui pengaruh timbal balik antara satu variabel dengan variabel lain. Dalam penelitian ini bertujuan mengetahui pengaruh aktivitas olah raga dan perilaku merokok terhadap hipertensi pada lansia.

Sampel dalam penelitian ini ditentukan berdasarkan (Notoatmodjo)

$$
\mathrm{n}=\frac{\mathrm{N}}{1+N \mathrm{~d}^{2}}
$$

Keterangan :

$\mathrm{N}=$ besar populasi

$\mathrm{n}=$ Besar sampel

$\mathrm{d}=$ Tingkat kepercayaan/ketepatan yang diinginkan

Sesuai dengan rumus tersebut 3. HASIL

didapatkan besar sampel :
2. Setelah mendapatkan ijin penelitian dilanjutkan dengan mengajukan ijin penelitian ke Balitbang Kabupaten Parigi Moutong Sulawesi Tengah.

3. Selanjutnya mengajukan ijin penelitian ke Dinas Kesehatan Kabupaten Parigi Moutong Sulawesi Tengah..

4. Setelah mendapat ijin dari dinkes, dilanjutkan pengajuan ijin penelitian ke Puskesmas Tomini Kabupaten Parigi Moutong Sulawesi Tengah.

5. Terakhir dilanjutkan kepada responden terpilih setelah memberikan informed consent dan responden menyetujui untuk ikut berpartisipasi dalam penelitian.

.Proses pengolahan data ada 4 yaitu editing, coding, scoring dan tabulating. Analisa data dalam penelitian ini menggunakan analisis univariat, bivariat dan multivariat. Etika pengambilan data dalam penelitian ini yaitu Informed consent, Anonymity (tanpa nama), Kerahasiaan (confidentiality).

1. Univariat

$$
\begin{aligned}
& \mathrm{N}=\frac{\mathrm{N}}{\mathrm{N}} \text { Tabel 1 Distribusi frekuensi } \\
& 1 .+\mathrm{N} \mathrm{d}^{2} \quad 0.05 \quad 2 \quad \text { responden berdasarkan } \\
& \mathrm{N}=\begin{array}{llll}
160 & \begin{array}{l}
\text { Puskesmas } \\
\text { Kecamatan }
\end{array} & \text { Tomini } \\
\text { Tomini }
\end{array}
\end{aligned}
$$

$\mathrm{N}=114 \quad$ Responden

Pengumpulan data aktivitas olah raga, perilaku merokok dan hipertensi menggunakan kuesioner.

Prosedur pengumpulan data aktivitas olah raga, perilaku merokok dan hipertensi dilakukan dengan alur sebagai berikut:

1. Mengajukan permohonan untuk melakukan penelitian kepada Ketua Yayasan Muhammadiyah.

\begin{tabular}{ccc}
\hline Variabel & f & $\%$ \\
\hline Aktivitas olah raga & & \\
Aktif & 61 & 53,6 \\
Tidak aktif & 53 & 46,4 \\
Perilaku merokok & & \\
Baik & 66 & 57,9 \\
Tidak baik & 48 & 42,1 \\
Hipertensi & & \\
Normal & 64 & 56,1 \\
Hipertensi & 50 & 43,9 \\
\hline
\end{tabular}

2. Bivariat 
Tabel 2 Distribusi variabel independen dan variabel dengan variabel dependen di Puskesmas Tomini Kecamatan Tomini Kabupaten Parigi Moutong Sulawesi Tengah Tahun 2019

\begin{tabular}{|c|c|c|c|c|c|c|}
\hline \multirow{3}{*}{$\begin{array}{c}\text { Variabel } \\
\text { independen }\end{array}$} & \multicolumn{4}{|c|}{ Kejadian Hipertensi } & \multirow{3}{*}{$\begin{array}{c}p- \\
\text { value }\end{array}$} & \multirow{3}{*}{ OR } \\
\hline & \multicolumn{2}{|c|}{ Hipertensi } & \multicolumn{2}{|c|}{ Normal } & & \\
\hline & $\mathrm{N}$ & $\%$ & $\mathrm{~N}$ & $\%$ & & \\
\hline \multicolumn{7}{|l|}{ Aktivitas } \\
\hline Tidak aktif & 36 & 67,9 & 17 & 32,1 & 0,000 & 9,021 \\
\hline Aktif & 14 & 23,0 & 47 & 77,0 & & \\
\hline \multicolumn{7}{|l|}{ Perilaku } \\
\hline Tidak baik & 31 & 64,6 & 17 & 35,4 & 0,001 & 4,991 \\
\hline Baik & 19 & 28,8 & 47 & 71,2 & & \\
\hline \multicolumn{7}{|l|}{ Jenis } \\
\hline \multicolumn{7}{|l|}{ Kelamin } \\
\hline Laki-laki & 9 & 24,3 & 28 & 75,7 & $0,0<5$ & 0,230 \\
\hline $\begin{array}{l}\text { Perempuan } \\
\text { Usia }\end{array}$ & 41 & 53,2 & 36 & 46,8 & & \\
\hline$\geq 60$ tahun & 29 & 46,0 & 34 & 54,0 & 0,904 & 0,942 \\
\hline$<60$ tahun & 21 & 41,2 & 30 & 58,8 & & \\
\hline \multicolumn{7}{|l|}{ Pendidikan } \\
\hline $\begin{array}{l}\text { Pendidikan } \\
\text { dasar }\end{array}$ & 41 & 43,6 & 53 & 56,4 & 0,791 & 1,198 \\
\hline $\begin{array}{l}\text { Pendidikan } \\
\text { menengah }\end{array}$ & 9 & 45,0 & 11 & 55,0 & & \\
\hline \multicolumn{7}{|l|}{ Pekerjaan } \\
\hline Bekerja & 36 & 51,4 & 34 & 48,6 & 0,495 & 0,647 \\
\hline $\begin{array}{l}\text { Tidak } \\
\text { bekerja }\end{array}$ & 14 & 31,8 & 30 & 68,2 & 0,495 & $0,04 \pi$ \\
\hline Sumber & & & & & & \\
\hline Informasi & & & & & & \\
\hline $\begin{array}{l}\text { Media } \\
\text { elektronik }\end{array}$ & 8 & 50,0 & 8 & 50,0 & 0,375 & 1,935 \\
\hline $\begin{array}{l}\text { Petugas } \\
\text { kesehatan }\end{array}$ & 42 & 42,9 & 56 & 57,1 & & \\
\hline
\end{tabular}

3. Multivariat

a. Seleksi bivariat

Tabel 3 Hasil Seleksi Bivariat berdasarkan faktor Independen dengan Hipertensi di Puskesmas Tomini Kecamatan Tomini Kabupaten Parigi Moutong Sulawesi Tengah Tahun 2019

\begin{tabular}{ccc}
\hline & Value & \\
\hline Aktivitas Olah & $0,000(<$ & $\sqrt{ }$ \\
raga & $0,25)$ & \\
Perilaku & $0,000(<$ & $\sqrt{ }$ \\
Merokok & $0,25)$ & \\
Jenis Kelamin & $0,005(<$ & $\sqrt{ }$ \\
& $0,25)$ & \\
Usia & $0,604(>$ & $\mathrm{X}$ \\
& $0,25)$ & \\
Pendidikan & $0,910(>$ & $\mathrm{X}$ \\
& $0,25)$ & \\
Pekerjaan & $0,042(<$ & $\sqrt{ }$ \\
& $0,25)$ & \\
Sumber & $0,594(>$ & $\mathrm{X}$ \\
Informasi & $0,25)$ &
\end{tabular}

b. Pemodelan regresi logistik multivariat hipertensi di Puskesmas Tomini Kecamatan Tomini Kabupaten Parigi Moutong Sulawesi Tengah

Tabel 4 Hasil pemodelan regresi logistik multivariat pertama hipertensi di Puskesmas Tomini Kecamatan Tomini Kabupaten Parigi Moutong Sulawesi Tengah Tahun 2019

\begin{tabular}{cccc}
\hline Variabel & Sig & OR & $95 \%$ CI \\
Aktivitas Olah raga & \multirow{2}{*}{0,000} & \multirow{2}{*}{8,358} & $233-$ \\
& & & 21,607 \\
Perilaku Merokok & 0,001 & 4,824 & $1,841-$ \\
& & & 12,641 \\
Jenis Kelamin & 0,017 & \multirow{2}{*}{0,223} & $0,065-$ \\
& & & 0,767 \\
Pekerjaan & 0,479 & 0,656 & $0,204-$ \\
& & & 2,109 \\
\hline
\end{tabular}

Table 5 Perhitungan perubahan nilai OR antara sebelum dan sesudah variabel pekerjaan dikeluarkan

\begin{tabular}{cccc}
\hline Variabel & $\begin{array}{c}\text { OR } \\
\text { pekerjaan } \\
\text { ada }\end{array}$ & $\begin{array}{c}\text { OR } \\
\text { pekerjaan } \\
\text { tidak ada }\end{array}$ & $\begin{array}{c}\text { Perubahan } \\
\text { OR }\end{array}$ \\
\hline Aktivitas olah raga & 8,358 & 8,116 & $2,9 \%$ \\
Perilaku merokok & 4,824 & 4,458 & $8,2 \%$ \\
Jenis kelamin & 0,223 & 0,283 & $-21,2 \%$ \\
Pekerjaan & 0,656 & - & - \\
\hline
\end{tabular}

Volume 4 Nomor 2, Desember 20193 
Table 6 Perhitungan perubahan nilai OR antara sebelum dan sesudah variabel jenis kelamin dikeluarkan

\begin{tabular}{cccc}
\hline Variabel & $\begin{array}{c}\text { OR jenis } \\
\text { kelamin } \\
\text { ada }\end{array}$ & $\begin{array}{c}\text { OR jenis } \\
\text { kelamin } \\
\text { tidak ada }\end{array}$ & $\begin{array}{c}\text { Perubahan } \\
\text { OR }\end{array}$ \\
\hline Aktivitas olah raga & 8,358 & 7,591 & $10,1 \%$ \\
Perilaku merokok & 4,824 & 4,898 & $-1,5 \%$ \\
$\begin{array}{c}\text { Jenis kelamin } \\
\text { Pekerjaan }\end{array}$ & 0,223 & - & - \\
\hline
\end{tabular}

c. Uji Interaksi

Tabel 7 Model terakhir multivariat pengaruh aktivitas olah raga dan perilaku merokok terhadap kejadian hipertensi di Puskesmas Tomini Kecamatan Tomini Kabupaten Parigi Moutong Sulawesi Tengah Tahun 2019

\begin{tabular}{|c|c|c|c|c|}
\hline Variabel & $\mathrm{B}$ & Sig & OR & $95 \% \mathrm{CI}$ \\
\hline $\begin{array}{c}\text { Aktivitas Olah } \\
\text { raga }\end{array}$ & 2,241 & 0,045 & 9,402 & $\begin{array}{l}1,056- \\
83,741\end{array}$ \\
\hline Perilaku Merokok & 2,284 & 0,029 & 9,819 & $\begin{array}{r}1,264- \\
76,269\end{array}$ \\
\hline Jenis Kelamin & $\overline{-}, 636$ & 0,531 & 0,530 & $\begin{array}{c}0,072- \\
3,870\end{array}$ \\
\hline $\begin{array}{l}\text { Aktivitas Olah } \\
\text { raga* Perilaku } \\
\text { Merokok }\end{array}$ & $\begin{array}{c}- \\
0,067\end{array}$ & 0,945 & 0,936 & $\begin{array}{c}0,141- \\
6,205\end{array}$ \\
\hline $\begin{array}{l}\text { Aktivitas Olah } \\
\text { raga* Jenis } \\
\text { Kelamin }\end{array}$ & $\begin{array}{c}- \\
0,164\end{array}$ & 0,887 & 0,848 & $\begin{array}{c}0,088- \\
8,171\end{array}$ \\
\hline $\begin{array}{l}\text { Perilaku } \\
\text { Merokok* Jenis } \\
\text { Kelamin }\end{array}$ & $\overline{1,015}$ & 0,372 & 0,362 & $\begin{array}{c}0,039- \\
3,374\end{array}$ \\
\hline
\end{tabular}

Tabel 8 Model terakhir multivariat pengaruh aktivitas olah raga dan perilaku merokok terhadap kejadian hipertensi di Puskesmas Tomini Kecamatan Tomini Kabupaten Parigi Moutong Sulawesi Tengah Tahun 2019

\begin{tabular}{ccccc}
\hline & & & & 83,741 \\
Perilaku Merokok & 3,282 & 0,038 & 9,632 & $1,264-$ \\
& & & 76,269 \\
Jenis Kelamin & $-0,293$ & 0,498 & 0,421 & $0,072-$ \\
3,870 \\
Perilaku Merokok * & & & & $0,019-$ \\
Aktivitas Olah raga & $-0,039$ & 0,102 & 0,118 & 4,380 \\
$\begin{array}{c}\text { Perilaku Merokok * } \\
\text { Jenis Kelamin }\end{array}$ & $-0,015$ & 0,404 & 0,472 & $0,267-$ \\
Aktivitas Olah raga & & & & 9,369 \\
* Jenis Kelamin & $-1,219$ & 0,742 & 0,392 & $0,012-$ \\
\hline
\end{tabular}

Tabel 9 Model terakhir multivariat pengaruh aktivitas olah raga dan perilaku merokok terhadap kejadian hipertensi di Puskesmas Tomini Kecamatan

Tomini Kabupaten Parigi Moutong Sulawesi Tengah Tahun 2019

\begin{tabular}{ccccc}
\hline Variabel & B & Sig & OR & $95 \%$ CI \\
\hline Aktivitas Olah & 2,417 & 0,017 & 8,024 & $1,104-$ \\
raga & & & & 21,399 \\
Perilaku Merokok & 3,025 & 0,042 & 7,213 & $1,025-$ \\
& & & 41,281 \\
Jenis Kelamin & $-0,492$ & 0,531 & 0,221 & $0,041-$ \\
6,931 \\
$\begin{array}{c}\text { Jenis Kelamin * } \\
\text { Aktivitas Olah }\end{array}$ & $-0,261$ & 0,206 & 0,132 & $0,088-$ \\
$\quad$ raga & & & & 5,846 \\
$\begin{array}{c}\text { Jenis Kelamin * } \\
\text { Perilaku Merokok } \\
\text { Aktivitas Olah } \\
\text { raga * Perilaku }\end{array}$ & $-0,187$ & 0,198 & 0,281 & $0,100-$ \\
Merokok & $-1,452$ & 0,318 & 0,392 & $0,128-$ \\
\hline & & & & 5,889 \\
\hline
\end{tabular}

Tabel 10Model terakhir multivariat pengaruh aktivitas olah raga, perilaku merokok dan jensi keamin terhadap kejadian hipertensi di Puskesmas Tomini Kecamatan Tomini Kabupaten Parigi Moutong Sulawesi Tengah Tahun 2019

\begin{tabular}{ccccc}
\hline Variabel & B & Sig & OR & $95 \%$ CI \\
\hline Aktivitas & 2,094 & \multirow{2}{*}{0,000} & 8,116 & $3,166-$ \\
Olah raga & & & 20,808 \\
Perilaku & 1,495 & 0,002 & 4,458 & $1,756-$ \\
Merokok & & & & 11,316 \\
Jenis & $-1,263$ & 0,017 & 0,283 & $0,100-$ \\
Kelamin & & & & 0,801 \\
\hline
\end{tabular}

\begin{tabular}{ccccc}
\hline Variabel & B & Sig & OR & $95 \%$ CI \\
\hline Aktivitas Olah raga & 3,195 & 0,022 & 10,239 & $1,056-$
\end{tabular}




\section{PEMBAHASAN}

1. Pengaruh Aktivitas Olah Raga terhadap Hipertensi

Berdasarkan hasil pengolahan data maka dapat dinyatakan bahwa diperoleh nilai signifikan antara pengaruh aktivitas olah raga tehadap hipertensi adalah sebesar 0,000 ( $p \leq$ 0,05). Hal ini menunjukan bahwa terdapat pengaruh aktivitas olah raga terhadap hipertensi. Responden yang tidak aktif dalam berolah raga mempunyai resiko atau peluang menderita hipertensi sebesar 9,021 dibandingkan responden yang aktif berolah raga.

Menurut peneliti bahwa terdapat pengaruh aktivitas olah raga terhadap hipertensi dikarenakan responden yang tidak aktif berolah raga dapat menyebabkan terjadinya penimbunan lemak dan aliran darah menjadi tidak lancar sehingga membuat jantung berdenyut lebih cepat dan tekanan darah menjadi meningkat. Sedangkan pada responden yang mempunyai kebiasaan olahraga $\geq$ 3 kali dalam seminggu dengan durasi minimal 20 menit perlatihan akan membuat makanan yang dikonsumsi tidak tersimpan menjadi lemak di dalam tubuh sehingga melancarkan pembuluh darah, jantung dapat bekerja lebih baik dan denyut nadi menjadi normal.

Sejalan dengan pernyataan Sharkey (2014) bahwa berolah raga yang teratur mengajarkan tubuh untuk mendistribusikan darah dengan lebih baik ke otot, sehingga lebih mengurangi beban kerja jantung.

Seperti yang dijelaskan oleh Widartho (2012) bahwa orang yang menderita hipertensi sangat dianjurkan untuk berolah raga secara teratur, karena olah raga banyak dihubungkan dengan pengelolaan hipertensi. Bagi penderita hipertensi semua bentuk olah raga baik, asal tidak menyebabkan kelelahan fisik. Tetapi ada pula olah raga yang tidak dianjurkan untuk penderita hipertensi, bahkan dilarang untuk dilakukan seperti tinju, karate, gulat karena akan memperparah.

Hasil penelitian ini sejalan dengan hasil penelitian yang dilakukan oleh Sanjaya (2013), dimana hasil penelitiannya menunjukan bahwa terdapat pengaruh antara aktivitas olah raga dengan hipertensi di Puskesmas Rendang Karang Asem Bali. Orang yang tidak aktif berolah raga mempunyai risiko hipertensi 10 kali lebih besar dibanding orang yang aktif berolah raga.

2. Pengaruh Perilaku Merokok terhadap Hipertensi

Berdasarkan hasil pengolahan data maka dapat dinyatakan bahwa diperoleh nilai signifikan antara pengaruh perilaku merokok terhadap hipertensi adalah sebesar 0,001 ( $p \leq$ $0,05)$. Hal ini menunjukkan bahwa terdapat pengaruh perilaku merokok terhadap hipertensi. Responden yang perilaku merokoknya tidak baik mempunyai resiko atau peluang menderita hipertensi sebesar 4,991 dibanding responden yang perilaku merokoknya baik.

Menurut peneliti bahwa terdapat pengaruh perilaku merokok terhadap hipertensi dikarenakan kandungan yang terdapat pada rokok sangat membahayakan tubuh, misalnya seperti nikotin yang dapat menyebabkan tekanan darah tinggi. Selain itu, zat yang terkandung dalam rokok seperti tar dapat meningkatkan pula tekanan darah. Kandungan yang ada pada rokok memaksa jantung memompa darah lebih kuat lagi yang menyebabkan tekanan darah meningkat. Sehingga pada responden yang mempunyai lama merokok tidak berisiko (merokok $\leq 1$ tahun) kecil kemungkinan untuk menderita hipertensi jika dibanding pada 
responden yang mempunyai lama merokok berisiko (merokok $>1$ tahun).

Sejalan dengan pernyataan Muhammadun (2012) bahwa nikotin dalam tembakau merupakan penyebab meningkatnya tekanan darah segera setelah isapan pertama. Seperti zat-zat kimia lain dalam asap rokok, nikotin diserap oleh pembuluh-pembuluh darah amat kecil di dalam paru-paru dan diedarkan ke aliran darah. Hanya dalam beberapa detik nikotin sudah mencapai otak. Otak bereaksi dengan nikotin dengan memberi sinyal pada kelenjar adrenal untuk melepas epinefrin (adrenalin). Hormon yang kuat ini akan menyempitkan pembuluh darah dan memaksa jantung untuk bekerja lebih berat karena tekanan yang lebih tinggi. Setelah merokok dua batang saja maka baik tekanan sistolik maupun diastolik akan meningkat 10 mmHg. Tekanan darah akan tetap pada ketinggian ini sampai 30 menit setelah berhenti mengisap rokok. Sementara efek nikotin perlahan-lahan menghilang, tekanan darah juga akan menurun dengan perlahan. Namun pada perokok berat tekanan darah akan berada pada level tinggi tersebut sepanjang hari.

Hasil penelitian ini sejalan dengan penelitian yang dilakukan oleh Warda (2011) di Puskesmas Cetasi II Kota Padang yang menemukan adanya pengaruh yang bermakna antara perilaku merokok, dengan nilai $p=$ 0,024. Seseorang yang perilaku merokoknya tidak baik mempunyai risiko 13 kali lebih besar menderita hipertensi dibanding orang dengan perilaku merokoknya baik.

3. Pengaruh Aktivitas Olah Raga dan Perilaku Merokok Secara BersamaSama Terhadap Hipertensi

Hasil analisa pada penelitian antara pengaruh bersama-sama variable bebas terhadap variabel terikat menunjukkan bahwa semua variabel memiliki nilai signifikan atau $p$ valuenya $\leq 0,05$. Hasil ini berarti secara statistik mempunyai pengaruh terhadap variabel terikat (hipertensi). Sementara variabel usia, pendidikan, pekerjaan, dan sumber informasi tidak mempunyai pengaruh terhadap variabel terikat (hipertensi) karena memiliki nilai signifikan $>0,05$.

Menurut peneliti hipertensi disebabkan karena responden tidak aktif berolah raga, perilaku merokok yang tidak baik dan responden yang berjenis kelamin laki-laki. Perilaku merokok merupakan suatu perbuatan yang tidak memiliki nilai positif dalam semua hal terutama pada kesehatan. Merokok merupakan awal yang mendatangkan berbagai jenis penyakit degeneratif yang mematikan, seperti kankerdan penyakit jantung. Nikotin dalam tembakau merupakan penyebab meningkatnya tekanan darah segera setelah hisapan pertama. Seperti zatzat kimia lain dalam asap rokok, nikotin diserap oleh pembuluhpembuluh darah amat kecil di dalam paru-paru dan diedarkan ke aliran darah. Hanya dalam beberapa detik nikotin sudah mencapai otak. Otak bereaksi terhadap nikotin dengan memberi sinyal pada kelenjar adrenal untuk melepas epinefrin (adrenalin). Hormon yang kuat ini akan menyempitkan pembuluh darah dan memaksa jantung untuk bekerja lebih berat karena tekanan yang lebih tinggi. Dengan mengisap sebatang rokok akan memberi pengaruh besar terhadap naiknya tekanan darah. Hal ini dikarenakan asap rokok mengandung kurang lebih 4000 bahan kimia yang 200 di antaranya beracun dan 43 jenis lainnya dapat menyebabkan kanker bagi tubuh.

Pada saat merokok, tekanan darah akan naik. Punya kebiasan merokok berarti berisiko mengalami hipertensi. Ditambah lagi, zat-zat 
beracun dalam merokok bisa merusak pembuluh darah. Bahkan orang yang jadi perokok pasif atau menggunakan tembakau jenis lain pun juga berisiko menderita hipertensi.

Sementara pada responden aktif dalam berolah raga dapat mengurangi tekanan darah bukan hanya disebabkan berkurangnya berat badan, tetapi juga disebabkan bagaimana tekanan darah tersebut dihasilkan. Tekanan darah ditentukan oleh dua hal yaitu jumlah darah yang dipompakan jantung per detik dan hambatan yang dihadapi darah dalam melakukan tugasnya melalui arteri. Olah raga dapat menyebabkan pertumbuhan pembuluh darah kapiler yang baru dan jalan darah yang baru. Dengan demikian hal yang menghambat pengaliran darah dapat dihindarkan atau dikurangi, yang berarti menurunkan tekanan darah. Walaupun kesanggupan jantung untuk melakukan pekerjaannya bertambah melalui olah raga, pengaruh dari berkurangnya hambatan tersebut memberikan penurunan tekanan darah yang sangat berarti.

Sementara pada responden yang berjenis kelamin laki-laki lebih tinggi risiko mengidap penyakit hipertensi dari pada perempuan. Lakilaki lebih banyak melakukan kebiasaan hidup yang bisa menimbulkan hipertensi seperti merokok, pemarah, mengkonsumsi minuman alkohol.

Prevalensi terjadinya hipertensi pada pria sama dengan wanita. Namun wanita terlindung dari penyakit kardiovaskuler sebelum menopause. Wanita yang belum mengalami menopause dilindungi oleh hormon estrogen yang berperan dalam meningkatkan kadar HDL. Kadar kolesterol HDL yang tinggi merupakan faktor pelindung dalam mencegah terjadinya proses aterosklerosis. Efek perlindungan estrogen dianggap sebagai penjelasan adanya imunitas wanita pada usia premenopause. Pada premenopause wanita mulai kehilangan sedikit demi sedikit hormon estrogen yang selama ini melindungi pembuluh darah dari kerusakan. Proses ini terus berlanjut dimana hormon estrogen tersebut berubah kuantitasnya sesuai dengan umur wanita secara alami.

Penelitian ini sesuai dengan penelitian Sugiharto (2014) yang membuktikan adanya pengaruh antara merokok dengan hipertensi dengan nilai $p=0,001$; $\mathrm{OR}=2,47$ dan $95 \%$ $\mathrm{CI}=1,44-4,23$.

\section{KESIMPULAN}

Ada pengaruh aktivitas olah raga dan perilaku merokok terhadap hipertensi pada lansia di Puskesmas Tomini Kecamatan Tomini Kabupaten Parigi Moutong Sulawesi Tengah tahun 2019.

\section{SARAN}

1. Diharapkan kepada pihak Puskesmas Tomni agar rutin melaksanakan penyuluhan kepada masyarakat khususnya penderita hipertensi tentang pengaruh gaya hidup terhadap tekanan darah, sehingga dapat menurunkan angka kejadian hipertensi.

2. Diharapkan lansia untuk melakukan olah raga secara teratur, sehingga dapat mencegah timbulnya masalah hipertensi.

3. Bagi peneliti selanjutnya, diharapkan agar hal-hal yang sudah ada dalam penelitian ini bisa menjadi acuan dan dapat dikembangkan terutama pada variabel-variabel yang belum diteliti.

\section{REFERENSI}

Arifin, Muhammad Hafiz Bin Mohd dan I Wayan Weta2, Ni Luh Ketut Ayu Ratnawati. 2016. Faktor-Faktor yang Berhubungan dengan Kejadian Hipertensi pada Kelompok Lanjut Usia di Wilayah Kerja UPT Puskesmas Petang I Kabupaten Badung Tahun 2016. Udayana 
: Program Studi Pendidikan Dokter, Fakultas Kedokteran, Universitas Udayana, Bagian/SMF Ilmu Kedokteran Komunitas dan Ilmu Kedokteran Pencegahan (IKK-IKP) Fak. Kedokteran Universitas Udayana

Kemenkes RI. 2014. Mencegah dan Mengontrol Hipertensi Agar Terhindar dari Kerusakan Organ Jantung, Otak dan Ginjal Infodatin Pusat Data dan Informasi Kementerian Kesehatan RI. Jakarta : Kemenkes RI

Muhammadun. 2012. Hidup Bersama Hipertensi Seringai Darah Tinggi Sang Pembunuh Sejati. Yogyakarta : In-Books.

Novitaningtyas, Tri. 2014. Hubungan Karakteristik (Umur, Jenis Kelamin, Tingkat Pendidikan) dan Aktivitas Fisik dengan Tekanan Darah pada Lansia di Kelurahan Makamhaji Kecamatan Kartasura Kabupaten Sukoharjo. Surakarta : Program Studi Gizi Fakultas Ilmu Kesehatan Universitas Muhammadiyah Surakarta

Rawasiah, Andi Besse dan Wahiduddin, Rismayanti. 2014. Hubungan Faktor Konsumsi Makanan dengan Kejadian Hipertensi pada Lansia di Puskesmas Pattingalloang. Makasar : Bagian Epidemiologi Fakultas Kesehatan Masyarakat Universitas Hasanuddin

Sanjaya, I.G. 2013. Hubungan antara Kebiasaan Olahraga dengan Hipertensi di Puskesmas Rendang Karang Asem. Denpasar : STIKes Bali.

Setyanda, Yashinta Octavian Gita dan Delmi Sulastri, Yuniar Lestari. 2015. Hubungan Merokok dengan Kejadian Hipertensi pada Laki-Laki Usia 35-65 Tahun di Kota Padang. Pendidikan Dokter FK Unand (Fakultas Kedokteran Universitas Andalas Padang, 2. Bagian Ilmu Gizi FK Unand, 3. Bagian Ilmu Kesehatan Masyarakat FK Unand
Sharkey, Brian. 2014. Kebugaran Kesehatan. Jakarta : PT Raja Grafindo Perkasa.

Sugiharto, A. 2014. Faktor-faktor Resiko Hipertensi pada Masyarakat (Studi Kasus di Kabupaten Karanganyar). Tesis. Semarang : Universitas Diponegoro.

Trihono. 2013. Riset Kesehatan Dasar Tahun 2013. Jakarta : Kementerian Kesehatan Republik Indonesia

Warda, S. 2011. Faktor Risiko Hipertensi di Puskesmas Cetasi II Kota Padang. Padang : UNP.

Widartho. 2012. Bahaya Hipertensi. Jakarta : Sunda Kelapa Pustaka. 